\title{
Yuliia Shevchenko
}

PhD of Economics, Deputy Director for Economic Affairs

«System Electronic Export» Ltd, Kyiv, Ukraine

E-mail: shevchenko-julia@ukr.net

ORCID: https://orcid.org/0000-0002-3602-1722

\section{Innovative transformation of agricultural enterprises in conditions of uncertainty}

\begin{abstract}
The purpose of the paper is an in-depth study of the innovative transformation of agricultural enterprises in the conditions of unpredictability, the need to spread and introduce new technologies that help reduce the effects of any crisis. Methodology. The rationale for choosing the agricultural sector corporation survey is based on the use of market capitalization and share price statistics over the past ten years, which clearly demonstrate the stable, moderate economic development of the corporate system. The study of innovative projects allows to demonstrate the state of the innovation sector within corporations of agriculture and food industry. The results of the paper are to emphasize the importance of maintaining the technologically advanced sector of agriculture, which will reduce the financial, fixed and variable costs of the enterprise. Cooperation between corporations, research institutes and non-profit organizations in the field of innovation will be able to improve the economic development of the host countries and start a new stage in the functioning of TNCs in the field of agro-industrial complex. Although TNCs in the food industry have a low market capitalization compared to the technological sector of the economy, they are the basis of one of the components of sustainable development, namely the environmental component. Limited resources encourage their rational use and careful treatment. Practical implications. Demonstration of successfully implemented innovation projects in the future will stimulate the management staff of any enterprise, regardless of ownership, to the rational use of own resources and sustainable development. The market capitalization of TNCs in the agro-industrial sector proves that obtaining permanent profits can reduce the impact of economic, environmental and social crises. Crisis waves and peaks will be smoothed out. Value/originality. Solving the problem of overcoming the consequences of unpredictability through innovative projects emphasizes the importance of a deeper and more thorough study of vivid and real examples of the introduction of innovative products by well-known transnational corporations. The agro-industrial sector depends on the available technologies, as the preservation of natural resources, public health and food safety are the main areas of existence of this sector of the economy.
\end{abstract}

\section{Keywords}

Agro-industrial complex, innovations, project, sustainable development, transnational corporations, transformation

JEL: F23, F50, O13, O16

\section{Introduction}

Statement of the problem. The economic system is in constant transformation, its elements are becoming more complicated, new technologies and innovations are emerging, which are changing the mechanism of work and ways of adapting to endogenous and exogenous factors. Enterprises of various forms of ownership try to comply with modern norms and legal framework of any level, from orders, instructions of enterprises to international agreements concluded between countries.

Unpredictability, i.e., the inability to predict events of economic, political, environmental or social nature cause the need to use the resources of the enterprise. Management staff begins to develop an emergency strategy for the existence and operation of the business unit, taking into account the current situation. To mitigate the effects of the crisis, transnational corporations (TNCs) create their own planning based on the concept of sustainable development, on the technological and innovative development of the global economic space.

Agro-industrial corporations have a significant influence on the policies of the host countries. However, the host countries receive from corporations a significant number of new technologies in the field of management. Also, by developing technologies, agro-industrial corporations help developing countries, and especially the poorest countries, to eliminate the problems associated with the elimination of hunger and compliance with goal 2 of sustainable development "Overcoming hunger".

Agricultural corporations have a rather low level of market capitalization compared to technological and innovative corporations. But their profits and activities are based on the implementation of optimal solutions and long-term activities. Factors of various etiologies adjust the direction of their activities and encourage greater investment of their own additional financial resources in research and development. Some corporations do not even have stocks or other securities placed on world stock markets. However, their transformational development is based on innovations that disseminate and create high-tech TNCs with the help of highly qualified workers, scientists, cooperation with international and national research institutes. Scientific progress, which generates new technologies, creates incentives for the safe and rational 
use of natural, human and financial resources. Balancing is the goal of economic development of the society of host countries and donor countries of investments, new technologies and innovations.

The study of the transformational development of TNCs in the field of agriculture is relevant and proves the need for further study of the spread of technologies to facilitate land cultivation, new equipment that would reduce the harmful effects on the environment and public health in any country.

Latest scientific progress and publications review. Many scientists provide an in-depth study of the innovative transformation of agricultural enterprises in the conditions of unpredictability and new areas of economic activity such as: Gereffi \& Michelle (2008), researchers at Harvard Business School (2021), experts of Pricewatershouse Coopers (2021), statistics of stock exchanges Nasdaq (2021) and Frankfurt (2021) and corporate specialists of Cargill (2021), Syngenta AG (2021), Nestle (2021), BASF (2021), Danone (2021) and Unilever (2021).

Their developments are relevant, interesting and detailed in the study of new technologies introduced within corporations. It is argued that a stable market capitalization can adjust long-term performance and save additional resources in order to reduce crises of any origin. They provide their own examples of the implementation of new developments and projects in agriculture and food. However, the directions of their innovative development need to be updated and studied in more detail.

The purpose and the problem of research. The study of examples of innovative development of agricultural TNCs forms a parallel between stable market capitalization and the involvement of new technologies, cooperation with small businesses, which play a key role in creating the corporation's image, disseminating and providing access of individuals and other legal entities activities to possibilities of use intellectual, physical and scientific results.

The dynamics of the value of one share of agricultural and food TNCs shows how recently the value of the whole complex of TNCs has fluctuated and how it was influenced by various global factors or, for example, changes in the rules and regulations of national legislation.

The purpose of the paper is a study of examples of implementation of innovative products by transnational corporations in the field of food and agricultural activities, which demonstrate a stable market capitalization and do not have very high performance.

The study of such processes proves that in crisis, unpredictable fluctuations of the economic global organism, stable and unhurried development of enterprises creates conditions for long-term operation.

It should be noted that the economic system consists of many components and elements, where each has an influence and coordinates the full range of relations between major counterparties.

Accordingly, modern scholars emphasize the importance of the value chain to create a complete economic cycle and improve the basic mechanisms of value added in enterprises of any level and form of ownership (Gereffi \& Christian, 2008). The agricultural complex depends on the value chain from the cultivation of crops to the production of finished food products. Innovative technologies reduce enterprise costs and improve the state of natural resources of any host country.
The thorough study of the technological level and technologies involved in the production process of transnational corporations will provide an opportunity to acquaint national economic entities with new advanced technologies, which is the main task of this paper.

The research methodology is the selection of a sample study of implemented technological projects of six large corporations such as: Nestle (Switzerland) (Nestle, 2021), Basf (Germany) (Basf, 2021), Syngenta Global (Switzerland) (Syngenta, 2021), Unilever (Netherlands) (Unilever, 2021), Danone (France) (Danone, 2021), Cargill (USA) (Cargill, 2021).

The paper uses a statistical research method to compare the market capitalization of selected corporations and the current state of the issue of shares in Nasdaq (Nasdaq, 2021) and Frankfurt (Frankfurt Stock Exchange, 2021) stock exchanges.

Such a comprehensive study detetmines the relevance of this study and requires further scientific monitoring to fully address the problem.

\section{Results of the research}

Review of the dynamics and market capitalization of transnational corporations. The value of corporations fluctuates constantly under the influence of various factors from social (declining incomes, savings of households and businesses, the emergence of threatening poverty, hunger, food shortages and finished food production) to environmental (global warming, rising carbon emissions, coral loss reef in Australia, etc.

For example, projects such as the construction of the Great Green Wall, the launch of The Global Carbon Project (GCP), the African and Latin American Resilience to Climate Change (ARCC) project, etc. will help unite global efforts to tackle climate change and implement a breakthrough in relations between TNCs and states that suffer from the irrational use of their own natural and other resources.

It should be noted that the stability of the market capitalization of food and agricultural TNCs has been observed over the past five years. According to research by PriceWatersHouseCoopers, the largest 100 companies (PriceWatersHouseCoopers, 2021) increased by $48 \%$. The market capitalization reached a record level of 31.7 trillion US dollars. Corporations from all over the world have a relative increase in market capitalization.

However, in contrast to the agricultural sector, the technological sector remains the largest in size and amounts to 10.5 trillion US dollars. Other sectors had strong volatility and a change in market capitalization from $25 \%$ to $75 \%$.

In turn, the issue of shares and the state of development of stock exchanges has increased in developing and emerging markets. The most attractive in all respects are the stock exchanges of India, Brazil, China, Singapore, Australia. The issue of shares on the stock exchanges of Hong Kong, New York and London decreased. Corporations in any sector have begun to trust the issuance of shares, their placement (listing) in developing countries (PriceWatersHouseCoopers, 2021).

Technological TNCs will have strong positions and shares in the global financial market in 2030. TNCs originating in the United States will compete with the Chinese market. The markets of Hong Kong and Taiwan 


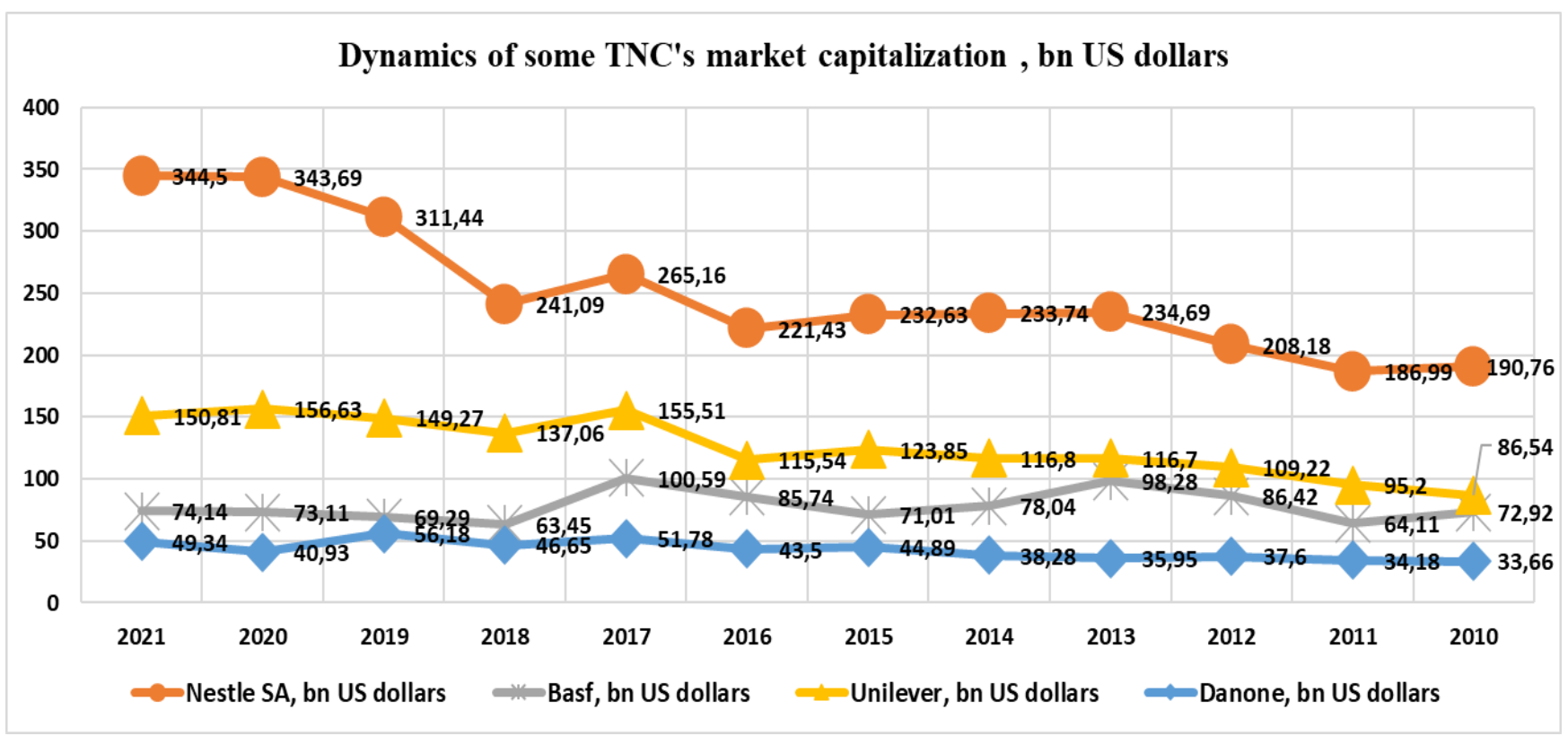

FIGURE 1 Dynamics of some TNC's market capitalization for 2010-2021, bn US dollars

Source: data is formed by author from PriceWatersHouseCoopers, 2021

will be especially attractive. The stock of shares with a stormy volume of 25 billion US dollars was carried out by the technological corporation, the leader in the field of e-commerce Alibaba Group. Chinese corporations are increasingly collaborating with start-ups at various levels, helping them to expand and develop, thus sharing experiences and technologies (PriceWatersHouseCoopers, 2021).

For the purpose of demonstration of the value development of corporations, we present on the basis of data of PriceWatersHouseCoopers, 2021, market capitalization of corporations Nestle (Switzerland), Basf (Germany), Unilever (Netherlands) and Danone (France) for 2010-2021 years (Figure 1).

These data show that the lowest market capitalization was in 2013 at Danone, then the largest - at Nestle in 2021 and amounted to 344.5 billion US dollars. It should be noted that in 2021, the reduction of market capitalization was in Unilever and amounted to 150.81 billion US dollars compared to 2020.

Another indicator of the success of corporations in the agricultural sector and the food industry, in our opinion, should consider the value of one share for 2016-2021 years (Figure 2).

We selected the same corporations for the study, as Syngenta and Cargill have no shares issued. Data for Nestle was generated using of Frankfurt Stock Exchange, 2021, where the shares of TNCs are issued. Other statistics were selected by us with the help of Nasdaq, 2021.

If we can see on Figure 2, the value of one share had a wave-like character. The corporation at Nestle had the highest share price in 2021 and amounted to 123.45 US dollars per share. The smallest is 14,718 US dollars per share of Danone.

That is why, the market capitalization for the period 2010-2021 for agricultural corporations did not experience strong shocks and unpredictable declines. A decrease in the value of one share was observed in 2018 for all surveyed corporations. However, this decrease was insignificant in terms of dynamic observation.

\section{Consideration of innovative projects of TNCs} in the agro-industrial sector.

Innovation emerges in the economic sphere as a result of huge investments in research and development by large corporations and other actors in international economic relations. The main legal basis was the introduction of the "Sustainable Development Goals", which were approved at the UN Summit on Sustainable Development, which will be valid until 2030.

It should be noted that corporations have begun to adhere to the goals and widely use them to maintain their own image and avoid unfair operations.

Researchers at Harvard Business School have studied the behaviour of a chemical corporation such as Procter \& Gamble and noted that the corporation has developed its own strategy for waste disposal and reducing the use of water for washing and other needs. The corporation's budget annually has an article for development and research in the amount of 2 billion US dollars. Managers and staff are constantly working with smaller businesses to find new technologies to reduce carbon emissions, use plastic and plastic packaging. However, the corporation gives its consumers a choice of which packaging to use (Harvard Business School, 2021).

In our opinion, the development of a strategy, which is set as a mandatory document by employees of the corporation in the manufacture of a particular product in agriculture or food provide inclusive development and regulatory relationship. That is, planning and careful study of the innovation market would help to improve the environmental situation of the host countries without harming the health of citizens and animals.

With the aim of supporting the development of inseparable relations in the field of cooperation and collaboration from industry to international level, each small or medium-sized enterprise is a key and vital counterparty. Since the relationship is established for the long term and with companies that have experience, good reputation, extensive supply system, appropriate levels of creditworthiness and reliability. 


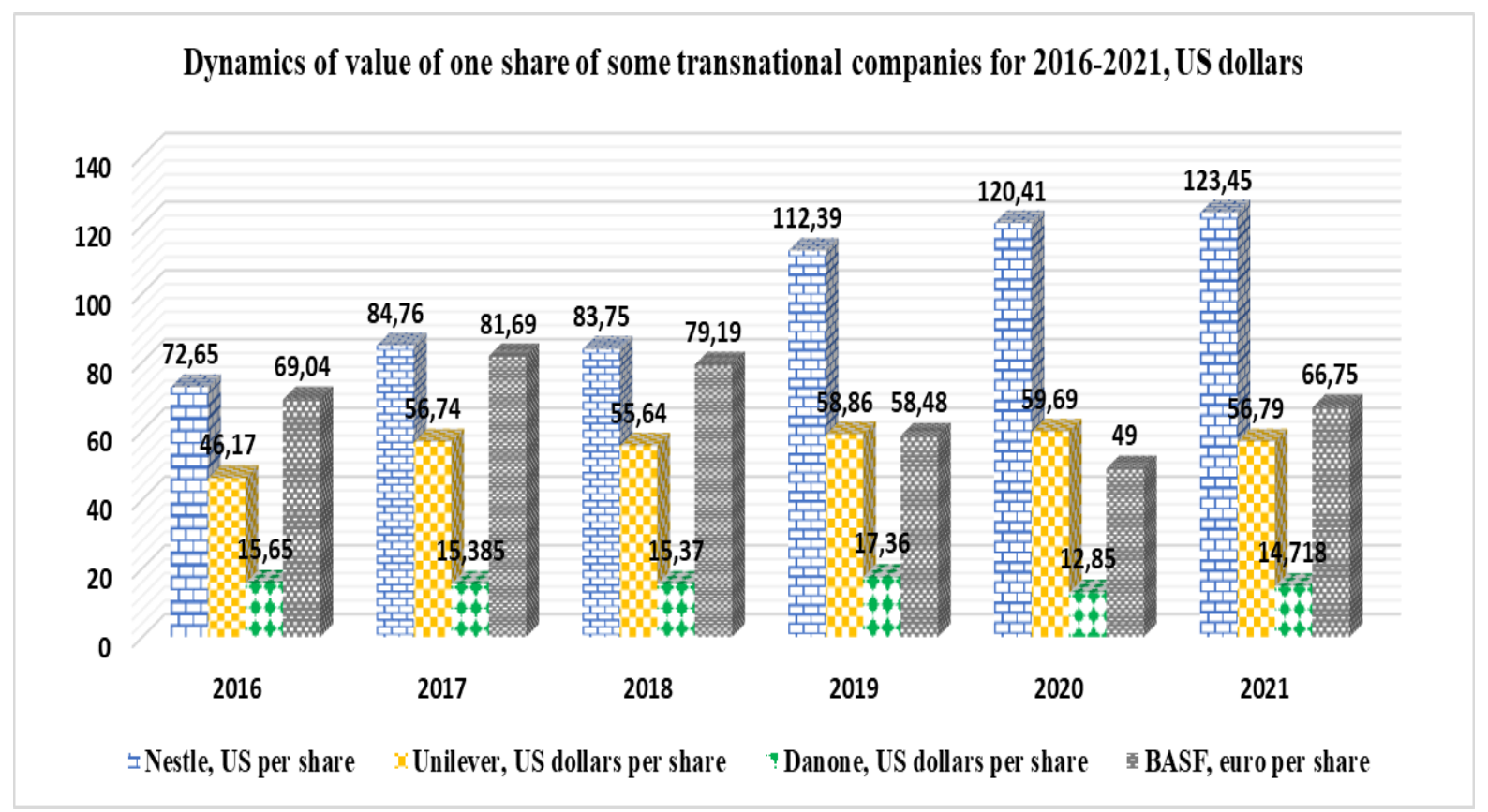

\footnotetext{
FIGURE 2 Dynamics of value of one share of some transnational corporations for 2016-2021, US dollars per share

Source: data is formed by author from Nasdaq. (2021); Frankfurt Stock Exchange (2021)
}

The food industry strongly depends on the created value chain. There are three stages in this interdependence, namely: the cultivation of crops, processing and production of finished products and the sale of finished products. For example, corporations such as McDonald's, Wendy's, WalMart depend on large suppliers of potatoes such as McCain Foods and J.R. Simplot. In turn, potato growers buy raw materials from large farmers such as United Fresh Potato Growers of Idaho. Whereas for cultivation the company needs herbicides, seeds that it gets from Bayer Crop Science (Gereffi \& Christian, 2008).

Therefore, economic relations are based on trust, the state of financial performance, constant discounts of partner companies. As a result of the disappearance from the economic cycle of at least one enterprise, the production capacity of another may decrease. Thus, new technologies are used, developed and disseminated in order to reduce financial market fluctuations, the effects of the COVID-19 pandemic and maintain competitiveness.

We should consider new technological projects and business strategies of such large corporations in the agricultural sector such as: Nestle (Switzerland), Basf (Germany), Syngenta Global (Switzerland), Unilever (Netherlands), Danone (France), Cargill (USA).

Cargill adheres to the principles of sustainable development and has developed a strategy until 2030, where the value chain will reduce $\mathrm{CO}_{2}$ emissions by $30 \%$ per ton of product, will introduce a complete abandonment of deforestation and the introduction of new safe materials (Cargill, 2021).

In addition to the corporation's main goals, in 2021 Cargill, along with corporations such as McDonald's, the Walmart Foundation and the World Wildlife Fund, will protect 1 million acres of land in need of safety and restoration. The project envisages that Cargill will join a three-month program of search and further cooperation with start-ups that have developed or are seeking financial resources to use technology in the areas of safe food management and development, wholesale and retail, and food safety (Cargill, 2021).

Another corporation, such as Danone, has launched a program to support the health of the elderly people in Brazil. Together with the medical staff, the corporation helps to reform the country's health care system and develop the medical, social and legal framework for its functioning. Danone's subsidiary Nutricia Netherlands, The Danone Ecosystem Fund, ONVZ Health Insurance, Philips and the non-profit organization Veiligheid NL have developed special nutrition, therapeutic care for the elderly people in the prevention of falls and accidents (Danone, 2021).

Innovative aspects of functioning of the corporation, in our opinion is not only the development of proper nutrition, but also cooperation with government agencies, organizations, health professionals to maintain a healthy life for the elderly people. The social direction of innovation in the future will help maintain a developed standard of living.

Unilever has implemented an environmental protection system through the use of liquefied natural gas. This application has reduced noise from heavy vehicles by $50 \%$, as well as $95 \%$ of carbon dioxide emissions. In countries such as India, the United States and Turkey, the corporation uses natural gas in its logistics systems. The safest raw material for trucks is the use of vegetable oil. This technology was introduced by a corporation in Sweden. Unilever began to use electric vehicles around the world. For example, in Europe, the United States and China, the company has signed contracts for the supply of products using electric trucks. Mexico uses a hybrid logistics system of trucks, half of the cars run on diesel and the other on electrical equipment (Unilever, 2021).

In turn, Syngenta has launched the project "ZERO by 40 ", which is supported by agricultural corporations, the non-profit Innovative Vector Control Consortium (IVCC). This project is expected to overcome such a dangerous disease as malaria by 2040 . This collaboration 
provided results and produced a special spray ACTELLIC ${ }^{\circledR}$ 300CS, which protects against the appearance of malaria mosquitoes, the main vectors of the disease (Syngenta, 2021).

The health of the citizens of the host countries should be one of the priorities for the development of society and the economy as a whole. The economic system, its results of activity create conditions for safe, inclusive development of the host countries and their people.

However, new technologies reduce both fixed and variable costs of the enterprise. For example, Basf enters the Chinese market due to the need for a chemical such as tert-butyl acrylate. It is envisaged that a plant for the production of this substance will be built in China. The corporation will increase production capacity for production of new chemicals such as propionic acid, propionic aldehyde, ethanolamines, ethyleneamines, and purified ethylene oxide. Propionic acid is necessary for long-term storage of food, which will help reduce their spoilage. Other substances will be used as herbicides and additives in the chemical, food industry, etc. (Basf, 2021).

In our opinion, Nestle's development of artificial meat in the laboratory in the food industry is interesting. The new technology is being developed at Lausanne designed by scientists from the corporation. The main reasons for the emergence of such technology are the reduction of land use, the rejection of GMO products, the refusal of meat consumption by many consumers, the increase in the number of vegetarians (Nestle, 2021).

Thus, consideration of such innovative projects makes it possible to compare the introduced technologies by domestic enterprises and global corporations in the food and agricultural spheres. It should be emphasized that agricultural corporations are developing a fairly extensive strategy for future operation, where they are rapidly gaining their market niche and developing, introducing new technologies, having sufficient financial resources.

\section{Conclusions}

Transnational corporations of the agricultural sector operate in the emergence, dissemination and transfer of technology, innovation. The problem of research into the introduction of such technologies in order to preserve the image, adhere to the concept of sustainable development, maintain economic security and stability is their rational and reasonable use. New technologies must be safe for society, public health, socially oriented and preserve the appropriate ecological state of the environment.

The market capitalization and the value of one share of well-known corporations specializing in the production of agricultural and food products have been stable over the last ten years. This trend proves that the moderate development and stable budget of the corporation allows to enter new markets as in the case of Basf, develop new chemicals, reagents and remain quite competitive for a long time.

Innovative development, the invention of new technologies promotes international cooperation between enterprises, expands the possibilities of the value chain and proves the existence of close, established economic ties between partner enterprises.

Bright examples of innovative projects of researched corporations reveal the need to involve highly professional workers, scientists in various fields of science, cooperation with research institutes. Such cooperation should be long-term and have a motivational component both for corporations wishing to operate in the future and for employees who will have an appropriate social package or bonus program.

Further research on the development of innovative projects by agricultural corporations is directly related to the need to overcome hunger in the poorest countries, improve living standards in developing countries, protect the environment, social support and overcome pandemics of malaria, COVID-19 and other dangerous diseases.

We will have no doubt that the agro-industrial complex is vital to ensure sustainable development and meet the Sustainable Development Goals by 2030. The innovative projects stimulate the implementation process of sustainable development. The exchange of international experience provides all counterparties necessary digital, information and innovative techniques, methods, mechanisms which help to face threats, economic challenges and crises. The low volume of international activity which are expressed in the moderate market capitalization of famous transnational corporations determines the future directions of functioning of the whole global economic system. That is why the strong relationship between states, transnational corporations and households shapes the networks of global value chain which improve international labour division and international trade.

\section{References}

[1] Basf (2021). BASF and SINOPEC to further expand their Verbund site in Nanjing, China. (2021). E-source: https://www.basf.com/global/en/media/news-releases/2021/08/p-21-275.html

[2] Cargill (2021). Cargill and Ecolab Support Emerging Technologies Across Food Supply Chain with New Techstars Farm to Fork Accelerator Class. E-source: https://www.cargill.com/2021/

[3] Cargill (2021). E-source: https://www.cargill.com/

[4] Cargill (2021). Grass, greenhouse gas and grazing: Why North America's prairies are key to cutting emissions. E-source: https://www.cargill.com/story/

[5] Danone (2021). Living Longer Better, It's Never Too Early To Nurture Your Health Capital. E-source: https://www.danone.com/stories/articles-list/living-longer-better.html

[6] Frankfurt Stock Exchange (2021). E-source: https://www.boerse-frankfurt.de/en

[7] Gereffi, Gary \& Christian, Michelle (2008). Food Production Systems, Trade, and Transnational Corporations: A Global Value Chains Approach to Consumption and Healthy Diets.

[8] Harvard Business School (2021). Procter \& Gamble's path to constructive disruption. E-source: https://www.strategy-business.com/article/Procter-and-Gambles-path-to-constructive-disruption

[9] Nasdaq (2021). E-source: https://www.nasdaq.com/market-activity/funds-and-etfs/basfx 
[10] Nestle (2021). Nestlé explores emerging technologies for cultured meat. E-source: https://www.nestle.com/randd/ news/allnews/nestle-explores-emerging-technologies-cultured-meat

[11] PriceWatersHouseCoopers (2021). Capital Markets in 2030. The future of equity capital. Markets. E-source: https://www.pwc.com/gx/en/audit-services/capital-market/publications/capital-markets-2030.pdf

[12] PriceWatersHouseCoopers Global Top 100 companies (2021). Global ranking of the top 100 public companies by market capitalisationhttps. E-source: https://www.pwc.com/gx/en/services/audit-assurance/publications/globaltop-100-companies.html

[13] Syngenta (2021). E-source: https://www.syngenta.com/ru/node/35998

[14] Unilever (2021). E-source: https://www.unilever.com/ 